\title{
Maternal Mortality and its Determinants among Wom- en Utilized Obstetrics and Gynecologic Services in Asella Teaching and Referral Hospital. Oromia Region, Ethiopia. 2018.
}

\author{
Girma Seboka ${ }^{1}$, Gizachew Abdeta ${ }^{2}$ and Ismael Kalayu ${ }^{2 *}$ \\ ${ }^{1}$ Assela health center, Ethiopia \\ ${ }^{2}$ Department of public health, Arsi University, Ethiopia
}

Submission: February 26, 2019; Published: April 09, 2019

*Corresponding author: Ismael Kalayu, College of Health Sciences, Arsi university, Assela, Ethiopia

\begin{abstract}
Background: Although maternal deaths worldwide have decreased by 45\% since 1990, 800 women still die each day from largely preventable causes. Every year about 412 women out of 100,000 live births die due to pregnancy related complications in Ethiopia. Thus, the aim of this study was to identify determinants of maternal death among mothers who utilized obstetrics and gynecological services in Asella Teaching and Referral Hospital. 2018.

Methods: An Institutional based retrospective cross-sectional study method was conducted on 553 charts of women who utilized Obstetrics and Gynecological services in Asella referral and Teaching Hospital from January 2017 to February 2017. The data was collected with structured check list and entered in to Epi info Version 7 software for data exploration and cleaning then exported to SPSS version 21 for analysis. Logistic regression was done to decide the association between dependent and independent factors. All explanatory variables with a p.v $<0.2$ in the crude analysis was included in the multiple logistic regression analysis. Crude and adjusted odds ratios were computed with the corresponding $95 \%$ confidence intervals. The predictor variables with a P-value $<0.05$ in multiple logistic regression were considered statistically significant.

Result: During the study period a total of 14,261 women got Obstetric and Gynecologic services in this Hospital, from which 11,081 gave live births. A total of 553 charts were included in this study and out of which 520 survived and 33 died implying that maternal mortality ratio was 297.8 per 100,000 live births. Delliances before reaching health facilities for the current problem (AOR $=9.0195 \%$ CI. 1.833, 40.262), delay before referring to the next level health facility (AOR=7.57 95\% CI.1.262, 45.411), presence of obstetrical complications (AOR $=12.395 \%$ CI.2.551, 59.67), obstructed labor (AOR=11.068, 95\% CI. 2.914, 42.040), Pre-existing medical problems (AOR=8.062, 95\% CI.2.232-29.118), and preeclampsia (AOR= $5.6695 \%$ CI. 1.37, 23.27) were found to be significant factors that caused the death of the mothers.

Conclusion and Recommendation: The maternal mortality ratio of this Hospital was high (297.8 per 100,000 live births). The immediate causes of maternal mortality of this study were hemorrhage (36.4\%), obstructed labor (33.3\%), prolonged labor (30.3\%), and hypertensive disorders (27.3\%). The health professionals and HEPs should have to improve awareness of the community about complications of pregnancy, danger sings, co-morbidity, ante natal care uptake and strengthen their awareness to avoid delay reaching the health facility. Conclusion: Hypertriglyceridemia was detected in most patients of T1D during DKA that significantly improved with insulin therapy. TG correlated with the DKA severity and BG levels. However, it did not affect glycemic control or insulin dose later.
\end{abstract}

Keywords: Maternal mortality ratio; Co-morbidity; Ante natal care; Pregnancy; Hemorrhage; Obstetric and Gynecologic; Maternal death; Maternal death surveillance; Data processing; Quality assurance

\section{Introduction}

\section{Background}

Maternal death is defined as the death of a woman while pregnant or within 42 days of the termination of pregnancy irrespective of the duration and site of the pregnancy, from any cause related to or aggravated by the pregnancy or its management but not from accidental or incidental causes [1]. In 1990, the World Health Organization estimated that 523,000 women died yearly from maternal causes [2].

The global adult lifetime risk of maternal mortality was 1 in 190 in 2013. While the adult lifetime risk of maternal mortality 
in women from sub-Saharan Africa was the highest at 1 in 38, in sharp contrast to 1 in 3,700 among women in developed countries [1]. This is almost similar with the study conducted by WHO which revealed that the estimated lifetime risk for maternal mortality in high-income countries is 1 in 3,400 [3].

According to WHO estimation maternal death decreased from 523,000 in 1990 to 289,000 in 2013 globally which accounts for $45 \%$ reduction. It was reduced from 990,000 to 510,000 for Sub-Saharan countries in the same year of interval with $49 \%$ reduction. The above report also revealed that, maternal death in Ethiopia reduced from 43,300 to 13,000 from 1990 to 2013 indicating a reduction by $38 \%$ and with $4 \%$ contribution to the overall global maternal death. These figures indicate that reduction in maternal death in Ethiopia is below the average for Sub-Saharan countries or the globe, despite the major progresses and achievements the country has made [4].

As shown earlier even though Ethiopia had reduced maternal deaths significantly, the number of deaths is still high according to WHO maternal death classification. Some hospital-based studies in the country show inconsistency in death trends. Therefore, further study is important to identify magnitude and determinants of maternal death. Hence, this study aims to objectively identify the magnitude and determinants of maternal mortality in Asella Teaching and referral Hospital, south east Ethiopia.

\section{Methods and Materials}

\section{Study area}

The study was conducted in Asella referral \& Teaching hospital found in Asella Town. It is located in Oromiya Regional state and $175 \mathrm{~km}$ away from South-east of the capital city of Addis Ababa. According to the 2007 Ethiopian census report and based on annual population growth rate, Asella has estimated total population of 105,997 and almost half 53,316 (50.3\%) were men and $52,680(49.7 \%)$ were women. The hospital was established in 1964G.C and Rebuilt in 1992 G.C. by Italian Government cooperation with a capacity of 250 beds. Starting from 2014 the hospital was re-established under Arsi University and has more than 1300 staffs of which 25 specialists, 71 GP, 200 nurses 40 laboratories, and 33 pharmacists. Internal medicine, surgery, obstetrics and gynecology, Emergency and pediatrics are the major departments in Asella referral and Teaching hospital. The hospital is providing care for South-eastern Ethiopia with a catchment population of about 5 million people.

\section{Study design and period}

An Institutional based retrospective cross sectional study design was conducted using secondary data of mothers who visited Asella Teaching and referral Hospital for maternal health service utilization from January, 2016 to February, 2016, charts of mothers who had died during the study period and charts of mothers who were survived while visited Asella Teaching and referral Hospital for maternal health service utilization was used. The sample population was all charts of died mothers and randomly selected charts of survived mothers during the study period.

\section{Sample size determination}

Sample size determination: The sample size for this study was determined by using single population proportion formula assuming 25\% prevalence (overall percentage of mother's deaths due to pregnancy-related complications) [5].

$$
\begin{gathered}
n=\frac{Z^{2} \frac{\alpha}{2} \times p(1-p)}{w^{2}} \\
n=\frac{(1.96)^{2} \times 0.25 \times(1-0.25)}{(0.05)^{2}} \\
n=\frac{3.8416 \times 0.25 \times 0.75}{0.0025} \\
n=\frac{0.7203}{0.0025}=288
\end{gathered}
$$

Where:

$\alpha=$ level of significance which can be obtain as 1-confidence level.

$\sigma=$ Standard deviation of the population

$\mathrm{w}=$ Maximum acceptable difference

$\mathrm{Z} \alpha / 2=$ Value under standard normal table for the given value of confidence level

The sample size for the second and the third objective was determined by double population proportion formula using Epi Info Version 7 assuming 95\% confidence, $80 \%$ power, $11.29 \%$ prevalence of exposure among controls (proportion of exposure among controls involved in health care decision making) and $22.58 \%$ prevalence of exposure among cases (Proportion of cases not involved in health care decision making)[6], odds ratio of 2.29, 1:4 case to control ratio, giving a desired sample size of 553. From the above exposure variables for the second and third objectives sample size 553 is the largest and it is greater than the first objective. So, 553 was the final sample size of this study.

\section{Data collection procedures}

Data on Maternal Death, socio demographic characteristics, Parity, ANC follow up length of labor, Co-morbidity and complication during pregnancy and labor was collected from charts of women using check lists which was developed from Maternal Death Surveillance and Response Technical Guideline 2014 in order to address the objective of the study [7]. The check list was prepared originally in English. Two Midwifery Nurses for data collection and 1 supervisor from Asella Town Health office who had past experience in survey data collection was recruited. Training for data collectors and supervisor was made for two days to ensure the quality of data. 


\section{Current Research in Diabetes \& Obesity Journal}

\section{Data processing and quality assurance}

Data was entered, cleaned and edited using Epi info 7 statistical software and then was exported to SPSS version 21.0 for further analysis. Descriptive statistics of the collected data was done for most variables in the study using Frequency tables, graphs, percentages. Bivariate analysis was conducted primarily to check which variables have association with the dependent variable individually. Variables found to have association with the dependent

Results

\section{Socio-demographic characteristics}

Table 1: Sample size determination for associated factors (for second objective)

\begin{tabular}{|c|c|c|c|c|c|c|}
\hline Exposure Variable & OR & Ratio & Power & C.I & P & Total Sample Size \\
\hline Involved in health care decision making & 2.29 & 4 & 80 & 95 & 11.29 & 553 \\
\hline Previous pregnancy complication & 2.97 & 4 & 80 & 95 & 6.1 & 482 \\
\hline ANC Care visits & 1.92 & 4 & 80 & 95 & 45.2 & 507 \\
\hline
\end{tabular}

The maternal mortality ratio of this Hospital was 297.8 per 100,000 live births. During the study period a total of 14,261 women got services in the Hospital, from which 11,081 gave live births. A total of 33 died women and 520 survived women were included in the study. Variables such as, ethnicity, educational status, marital status, occupation, and income were incomplete in

most of the charts: As a result, they were excluded from analysis. Most of the participants, 217 (39.2\%) in this study were in the age group of 25-29 years. Out of died women 10 (30.3\%) were from the age group of 25-29 years old. Half of the participants were from the rural community. Nearly three fourth of maternal death $24(72.7 \%)$ was also from rural residences (Table 1$)$.

\section{Obstetric and delivery history}

Table 2: Socio-demographic and Obstetric characteristics of women utilized obstetrical and gynecological services from 2016 -2017 in Asella referral and Teaching Hospital-2018

\begin{tabular}{|c|c|c|}
\hline Variable & Frequency (n) & Percent (\%) \\
\hline \multicolumn{3}{|l|}{ Age of women } \\
\hline $20-24$ & 174 & 31.5 \\
\hline $25-29$ & 217 & 39.2 \\
\hline $30-34$ & 77 & 13.9 \\
\hline$>=35$ & 50 & 9 \\
\hline \multicolumn{3}{|c|}{ Place of residence } \\
\hline Urban & 280 & 50.6 \\
\hline Rural & 273 & 49.4 \\
\hline \multicolumn{3}{|c|}{ Number of pregnancies } \\
\hline Primi-gravida & 229 & 41.4 \\
\hline $2-3$ & 211 & 38.2 \\
\hline $4-5$ & 51 & 9.2 \\
\hline$>5$ & 62 & 11.2 \\
\hline \multicolumn{3}{|c|}{ Number of delivery } \\
\hline Primipara & 229 & 41.4 \\
\hline $2-3$ & 211 & 38.2 \\
\hline $4-5$ & 51 & 9.2 \\
\hline$>=5$ & 62 & 11.2 \\
\hline \multicolumn{3}{|l|}{ Attended ANC } \\
\hline Yes & 437 & 79 \\
\hline No & 116 & 21 \\
\hline Place of ANC atten & & \\
\hline
\end{tabular}




\section{Current Research in Diabetes \& Obesity Journal}

\begin{tabular}{|c|c|c|}
\hline HP & 113 & 20.4 \\
\hline HC & 241 & 43.6 \\
\hline Hospital & 117 & 21.2 \\
\hline Private health facility & 80 & 14.5 \\
\hline
\end{tabular}

Regarding to obstetric and delivery history, 229 (41.4\%) were gravid 1 and 211 (38.2 \%) were in parity 2-3. Majority, 437 $(79.0 \%)$ were attending ANC. From the total women, 131 (23.7 $\%$ ) were come to the hospitals through referral due to different complications. One hundred sixty-two (29.3\%) of the women were developed complication during labor. However, 394 (71.2 $\%)$ of women were delivered by spontaneous vaginal delivery (SVD). More than two third, 391 (70.7\%) of the births were at-

Table 3: Pre-existing medical problems among women utilized obstetrical and gynecological services from 2016-2017, in Asella Referral and Teaching Hospital -2018

\begin{tabular}{|c|c|c|}
\hline Variable & Frequency & Percent (\%) \\
\hline Pre-existing medical problems & & 5.6 \\
\hline Yes & 31 & 94.4 \\
\hline No & 522 & 4.5 \\
\hline Anemia & 25 & 95.5 \\
\hline Yes & 528 & 0.4 \\
\hline No & & 99.6 \\
\hline Malaria & 2 & \\
\hline Yes & 551 & 0.2 \\
\hline No & & 99.8 \\
\hline Tuberculosis & 1 & \\
\hline Yes & 552 & \\
\hline No & & \\
\hline Heart Failure & 3 & 9.5 \\
\hline Yes & 550 & \\
\hline No & & \\
\hline
\end{tabular}

\section{Obstetric complications}

Thirty-one $(5.6 \%)$ of women had pre-existing medical problems, of those anemia accounts $25(80.6 \%)$. Whereas, $12(48 \%)$ of those with anemia were died. Taking into account risk during

antenatal period, $109(19.7 \%)$ of the women were presented with different antenatal risks of which, Hypertension was the most common that accounts 35 (32.1\%). From these, 9(25.7\%) were died. From total women who had abnormal puerperium only $27.3 \%$ of them were survived (Table 4).

Table 4: Presence of Antenatal Risks among women utilized obstetrical and gynecological services from 2016-2017, in Asella Referral and Teaching Hospital -2018

\begin{tabular}{|c|c|c|}
\hline Variable & Frequency & Percent (\%) \\
\hline Presence of ANC risks & & 19.7 \\
\hline Yes & 109 & 80.3 \\
\hline No & 444 & 6.3 \\
\hline Hypertension & & 93.7 \\
\hline Yes & 35 & 5.1 \\
\hline No & 518 & 94.9 \\
\hline Ant- partum Hemorrhage & 28 & \\
\hline Yes & 525 & \\
\hline No & & \\
\hline Multiple gestation & 15 & 2.7 \\
\hline
\end{tabular}




\section{Current Research in Diabetes \& Obesity Journal}

\begin{tabular}{|c|c|c|}
\hline No & 538 & 97.3 \\
\hline Previous C/S & & 4.7 \\
\hline Yes & 26 & 95.3 \\
\hline No & 527 & 0.4 \\
\hline Placenta praevia/Abraptio Placenta & 6 & 99.6 \\
\hline Yes & 551 & \\
\hline No & & \\
\hline Mal-presentation/Mal-Position & 15 & 2.5 \\
\hline Yes & 539 & 97.5 \\
\hline
\end{tabular}

From the study participants more than half $327(58.1 \%)$ had developed different complications. $43(13.2 \%)$ of them were developed PPH of which 12(27.9\%) had died. Out of those who developed complications Pre-eclampsia/eclampsia and APH accounts for 35(10.7\%) each, and Obstructed labor, Prolonged labor and PROM accounts for 61(18.7\%), 107(32.7\%) and 57(17.4\%)

respectively. From died women Pre-eclampsia/eclampsia, Obstructed labor and prolonged labor accounts 9(27.3\%), 11(33.3) and $10(30.3 \%)$ respectively. More than two third $(71.2 \%)$ of the delivery was spontaneous vaginal delivery and $21.7 \%$ was by $\mathrm{C} /$ Section. Almost all 31(93.9\%) of death occurred during postpartum period.

\section{Causes of maternal death}

Table 5: Obstetric complications among women utilized obstetrical and gynecological services from 2016-2017, in Asella Referral and Teaching Hospital -2018

\begin{tabular}{|c|c|c|}
\hline Variable & Frequency & Percent (\%) \\
\hline \multicolumn{3}{|c|}{ Obstetric Complication } \\
\hline Yes & 327 & 58.1 \\
\hline No & 226 & 40.9 \\
\hline \multicolumn{3}{|c|}{ Pre-eclapsia/ Eclapsia } \\
\hline Yes & 35 & 6.3 \\
\hline No & 518 & 93.7 \\
\hline \multicolumn{3}{|c|}{ Ant-partum Hemorrhage } \\
\hline Yes & 35 & 6.5 \\
\hline No & 518 & 93.7 \\
\hline \multicolumn{3}{|c|}{ Post-partum Hemorrhage } \\
\hline Yes & 43 & 7.8 \\
\hline No & 510 & 92.2 \\
\hline \multicolumn{3}{|c|}{ PROM/Sepsis } \\
\hline Yes & 57 & 10.3 \\
\hline No & 496 & 89.7 \\
\hline \multicolumn{3}{|c|}{ Obstructed Labor } \\
\hline Yes & 61 & 11 \\
\hline No & 493 & 89 \\
\hline \multicolumn{3}{|c|}{ Prolonged Labor } \\
\hline Yes & 107 & 19.5 \\
\hline No & 505 & 80.5 \\
\hline \multicolumn{3}{|c|}{ Multiple gestation } \\
\hline Ye & 20 & 3.6 \\
\hline No & 533 & 96.4 \\
\hline \multicolumn{3}{|c|}{ Uterine Rupture } \\
\hline Yes & 7 & 1.3 \\
\hline No & 546 & 98.7 \\
\hline
\end{tabular}




\section{Current Research in Diabetes \& Obesity Journal}

\begin{tabular}{|c|c|c|}
\hline IUFD & & \\
\hline Yes & 20 & 3.6 \\
\hline No & 533 & 96.4 \\
\hline
\end{tabular}

According to this finding, majority (93.4\%) of the maternal deaths in this Hospital were due to direct obstetric causes in which hemorrhage was the leading cause of maternal death accounting for $36.4 \%$, followed by obstructed labor (33.3\%).The rest causes of maternal death were prolonged labor (30.3\%), pre-eclampsia/ eclampsia (27.3\%), APH (21.2\%), and sepsis (9.1\%).Most of them $24(72.7 \%)$ died due to delay one \& three (Table 5).

\section{Factors associated with maternal mortality}

There is strong association between delay before reaching Health facility for the current problem and maternal mortality. That is women who were delayed before reaching Health facility for the current problem were 9.01 times more at risk for death than those who reach health facility with- out delay. AOR=9.01, 95\% CI. $(1.83,40.26)$ This finding is also supported by qualitative study as shown below: - A 33 years old mother came from rural said that "because of cultural influence and past experience many women could not make a decision to go to health facility on time, and some

may give birth at home. This delay or giving birth at home may lead to prolonged labor or complication which may end up with death". Women who develop pre-eclampsia/eclampsia were 5.66 times more at risk for death than those without pre-eclampsia/eclampsia $\mathrm{AOR}=5.66,95 \% \mathrm{CI}(1.37,23.27)$. Similarly, presences of obstetric complications were significantly associated with maternal mortality. Women who develop different obstetric complications were 12.3 times more at risk for death compared to counterparts (AOR=12.3, 95\% CI.2.55, 59.67). In addition, APH was another determinant for maternal mortality. Women who developed APH were 6.639 times more at risk when compared to their counter parts (AOR=6.639.95\% CI.1.029, 42.841). This is also supported by qualitative analysis done using FGD that, A 28 years old woman argued that "women may experience bleeding during pregnancy because of various causes like after falling or after lifting heavy materials and as to my knowledge if woman faces bleeding during pregnancy, this may endanger the life of fetus and woman (Table 6).

Table 6: Causes of death and factors according to the three delays of women utilized gynecologic and obstetric services in Asella Referral and Teaching Hospital. 2018

\begin{tabular}{|c|c|c|}
\hline Variable & Frequency & Percent (\%) \\
\hline \multicolumn{3}{|l|}{ APH } \\
\hline Yes & 7 & 1.3 \\
\hline No & 546 & 98.7 \\
\hline \multicolumn{3}{|l|}{ PPH } \\
\hline Yes & 12 & 2.2 \\
\hline No & 541 & 97.8 \\
\hline \multicolumn{3}{|c|}{ Pre-Eclapsia/Eclapsia } \\
\hline Yes & 9 & 1.6 \\
\hline No & 544 & 98.4 \\
\hline \multicolumn{3}{|l|}{ Sepsis } \\
\hline Yes & 3 & 0.5 \\
\hline No & 550 & 99.5 \\
\hline \multicolumn{3}{|c|}{ Prolonged Labor } \\
\hline Yes & 10 & 1.8 \\
\hline No & 543 & 98.2 \\
\hline \multicolumn{3}{|c|}{ Obstructed Labor } \\
\hline Yes & 11 & 2 \\
\hline No & 542 & 98 \\
\hline \multicolumn{3}{|l|}{ Delay One } \\
\hline Yes & 24 & 4.3 \\
\hline No & 529 & 95.7 \\
\hline \multicolumn{3}{|l|}{ Delay Two } \\
\hline Yes & 2 & 0.4 \\
\hline No & 551 & 99.6 \\
\hline Delay Three & & \\
\hline
\end{tabular}




\section{Current Research in Diabetes \& Obesity Journal}

\begin{tabular}{|c|c|c|}
\hline Yes & 24 & 4.3 \\
\hline No & 529 & 95.7 \\
\hline
\end{tabular}

Again, those who had delayed before referral to the next level health facility were 7.57 times more likely to die than their complements (AOR=7.57(1.262-45.411). Strong association was also found between women with PPH and maternal mortality. That is women who had PPH were 14.23 times more at risk for death than

also in line with qualitative FGD, another 31 years old lady from Asella Town said that "women who do not go to health facility for ANC and that attempt to give birth at home may face retained placenta which may lead to excessive bleeding, in turn may lead to death because of blood loss". who had no complication (AOR=14.23 95\% CI.4.52-44.85) This is

Table 7: Bivariate and multivariate logistic regression analysis of factors associated with maternal mortality in Asella Referral \& Teaching Hospital $(n=553), 2018$

\begin{tabular}{|c|c|c|c|c|}
\hline \multirow{2}{*}{ Variable } & \multicolumn{4}{|c|}{ Maternal death } \\
\hline & Yes & no & COR $(95 \% \mathrm{CI})$ & AOR $(95 \% \mathrm{CI})$ \\
\hline \multicolumn{5}{|c|}{ Pre-existing medical diseases } \\
\hline Yes & 13 & 18 & 18.13(7.81,42.07) & $9.48(2.51,35.82)$ \\
\hline No & 20 & 502 & 1 & 1 \\
\hline \multicolumn{5}{|c|}{ Pre-eclampsia/Eclampsia } \\
\hline Yes & 9 & 25 & $7.43(3.13 .17 .64)$ & $5.66(1.37-23.27)$ \\
\hline No & 24 & 495 & 1 & 1 \\
\hline \multicolumn{5}{|c|}{ A.P. Hemorrhage } \\
\hline Yes & 8 & 26 & $6.08(2.50,14.78)$ & $6.64(1.03,42.84) *$ \\
\hline No & 25 & 494 & 1 & 1 \\
\hline \multicolumn{5}{|c|}{ P.P. Hemorrhage } \\
\hline Yes & 6 & 4 & $28.67(7.64,107.63)$ & $14.23(4.52-44.85)$ \\
\hline No & 27 & 516 & 1 & 1 \\
\hline \multicolumn{5}{|c|}{ Delay before reaching HF for current problem } \\
\hline Yes & 19 & 41 & $15.86(7.41,33.92)$ & $9.01(1.83,40.26) *$ \\
\hline No & 14 & 479 & 1 & 1 \\
\hline \multicolumn{5}{|c|}{ Obstetric Complication } \\
\hline Yes & 20 & 68 & $10.23(4.86,21.51)$ & $12.34(2.55,59.67)$ \\
\hline No & 13 & 452 & 1 & 1 \\
\hline \multicolumn{5}{|l|}{ Sepsis } \\
\hline Yes & 3 & 6 & $8.56(2.04,35.94)$ & $0.027(.001, .69)$ \\
\hline No & 30 & 514 & 1 & 1 \\
\hline \multicolumn{5}{|c|}{ Obstructed Labor } \\
\hline Yes & 12 & 10 & $4.98(1.54,16.10)$ & $11.06(2.91-42.04)$ \\
\hline No & 21 & 510 & 1 & 1 \\
\hline \multicolumn{5}{|c|}{ Delay before referred to next health facility } \\
\hline Yes & 19 & 8 & 1 & 1 \\
\hline No & 4 & 100 & $0.017(0.005-0.062)$ & $7.570(1.262-45.411)$ \\
\hline
\end{tabular}

On the other hand, the likelihood of maternal death increases with the occurrence of pre-existing medical problems. Those who had pre-existing medical problems were 8.062 times more at risk of death than women who had no co-morbidity (AOR=8.062, $95 \%$ CI.2.23, 29.12). This is also in line with qualitative study as shown below- A 30 years old lady argued that "concerning maternal death in Asella Teaching and referral Hospital disease like HIV/AIDS and anemia if not early identified and get treatment it may end with maternal death" (Table 7).

\section{Discussion}

Maternal death in our country is very high as shown by different reports and reviews. As 2015 combined reports of WHO, UNICEF, World Bank and UNFPD, the current MMR of Ethiopia was 353 per 100,000 live births [8]. As shown in 2016 EDHS, the current National MMR was 412/100,000 live births, [5]. The general MMR in this hospital was 297.8 per 100,000 live births which is lower than the National estimate. How-ever it is far higher than the national target planned for 5 years MMR which is $199 / 100,000$ live births as indicated in health sector transformation plan [9]. 


\section{Current Research in Diabetes \& Obesity Journal}

It is also lower than the study conducted in JUSH, Mizan-Tepy University Teaching and Bonga Hospital and in Tanzania, which were 857,960 and 412 respectively. This could be because of under reporting in this Hospital due to fear of accountability. How-ever it is greater than the study conducted in Tigry which is 266 per 100,000 live births. This might be because of that the study conducted in Tigry was based on community in contrast to this study.

Another reason might be as shown by HSTP report decrease in occurrences of maternal death in this hospital might be because of increasing awareness of the community about institutional delivery, organizational and policy factors such as infrastructure building, service expansion and human power development which may contribute a lot. The other factor might be a country wide mobilization to decrease death of mother with slogan of "no mother should die while she gave life." Further -more, implementation of high impact interventions including antenatal care, skilled birth services, BEmONC, CEmONC programs and ambulance services for accelerating the reduction of maternal mortality were other factors which may contribute for the reduction of maternal mortality [9].

The immediate causes of maternal death were hemorrhage, obstructed labor, pre-eclampsia/eclampsia, prolonged labor and uterine rupture. This implies that, most $(93.4 \%)$ of the maternal deaths in this Hospital were due to direct obstetric causes. This is almost similar with the study conducted in Nigeria which revealed that the most common direct causes of maternal deaths were hemorrhage $34.6 \%$, sepsis $28.3 \%$, eclampsia $23.6 \%$ [10]. This is also similar with the study conducted in Namiba which revealed that Hemorrhage (37.8\%), eclampsia $(24.4 \%)$ and puerperal sepsis $(23.3 \%)$ were the leading causes of direct causes of maternal deaths [11].

The similarity might be because they are Sub-Saharan countries with almost similar socio-economic characteristics. However, the study conducted in Tigray had shown that major causes of maternal deaths were hemorrhage and pregnancy induced hypertension accounting for $46 \%$ and $19 \%$, respectively which is greater than this study [6]. The difference might be because of under reporting in this Hospital. The study conducted in Tanzania also revealed that the main direct causes of maternal death was Hemorrhage accounting for $28 \%$ of maternal deaths, followed by eclampsia (19\%) [12]. This is again supported by another study conducted in Nigeria which showed that Hemorrhage and eclampsia account $23.8 \%$ and 16.7 respectively were leading cause of maternal death [13]. These studies were lower than our study might be because of health system difference.

A Systematic review done on causes of maternal death by WHO showed that, Hemorrhage (27.1\%) was the leading direct cause of maternal death worldwide. Pregnancy induced hypertension was the second most common direct cause worldwide [3]. These were lower than our study might be because of that WHO took average estimation of the countries.
The determinant factors of maternal death in this Hospital were delay before reaching Health facility for the current problem. Women who delay before reaching health facility were 9.01 times more at risk for death than those who reach without delay. (AOR $=9.01(95 \%$ CI.1.833,40.262). This finding was in line with a study conducted in Namibia which revealed that women with delay before reaching health facility were more likely at risk of death than those not delayed [11]. This is again supported by a community-based study conducted in Tigray revealed that in more than $50 \%$ of the deaths "Poor health seeking behaviors" and lack of transportation were described as the obstacles to access services [6].

In this study, the likelihood of maternal death increases with the occurrence of pre-existing of medical problems. Those who had pre-existing of medical problems were 8.062 times more at risk of death than women who had no problems. (AOR=8.062, $95 \%$ CI.2.23, 29.12). This finding is consistent with study conducted in public hospital of Tigray, which revealed that women who had medical problems were 5.58 times more at risk of death than those without medical problems. (AOR=5.58,95\% CI.2.17,14.30) [6].

It also consistent with study done in JUSH which showed that women presented with pre-existing medical problems were 9.631 times more at risk of death than those not had pre-existing medical problems. (AOR=9.63,95\% CI $(3.14,29.58)$ Another risk factor which was significant in this study was obstructed labor. Women with obstructed labor were 11.068 times at risk to die than their counter parts. $(\mathrm{AOR}=11.068,95 \% \mathrm{CI}, 2.914,42.040$.

Presences of obstetric complications were also significantly associated with maternal mortality. Women who developed different obstetric complications were 12.3 times more at risk for death than their counterparts (AOR $=12.3(2.551,59.67)$. This finding is consistent with study conducted in Mizan-Tepi University Teaching and Bonga General Hospital, which revealed that women who had obstetric complication were 7.2 times at risk of maternal death than women who had no obstetric complications. (AOR=7.2 $95 \%$ CI.3.08, 16.72) [14]. These complications increase the risk of dying in different ways. Mal-presentation prolongs labor in intra-partum period. Prolonged labor will in turn expose the women for infections and hemorrhage. It might be explained by fatigued uterus. That is if pregnancy is post term, most of the time labor is initiated by induction which results in fatigue uterus which exposes the women for postpartum hemorrhage.

In addition, APH was another determinant for maternal mortality. Women who develop APH were 6.639 times more at risk to die than their counter parts $(A O R=6.639(1.029,42.84)$. Those who had ante or intra-natal risks like placenta praevia, Abruption placenta, and uterine rupture were the main causes for APH. This risk together with uterine rupture might be the major source of concealed and revealed hemorrhage that finally the most prominent cause of death. 


\section{Conclusion and Recommendation}

The MMR of this Hospital was high (297.8 per 100,000 live births). The immediate causes of maternal mortality of this Hospital were Hemorrhage, obstructed labor, hypertensive disorders, prolonged labor and uterine rupture. Most of (93.4) the maternal deaths in this Hospital were due to direct obstetric causes and majority of the deaths occurred at the age groups of 25-29 years.

The determinant factors were delayed before reaching health facility for the current problem, delayed before referring to the next level health facility, presence of obstetric complications, presence of obstructed labor and pre-existing medical problems were risk factors for maternal death.

Based on the findings from this study the following recommendations were made. The health professionals and HEPs should have to improve awareness of the community about complications of pregnancy, danger sings, co morbidities, ANC uptake and strengthen their awareness to avoid delay reaching the health facility when needed. They also should have to improve timely intervention to avoid delayed intervention and timely referral to the next level health facility. Service provision in Hospitals should be strengthened to reduce death in intra-partum period and post-partum period (particularly after operative delivery) and to avoid prolonged labor. Follow up, monitoring and evaluation of counseling, health education and quality of services provided by health providers in health centers and district hospitals should be.

\section{References}

1. (2014) Trends in Maternal Mortality: 1990 to 2013. WHO, p. 1-56.

2. Zureick-Brown S, Newby H, Chou D, Mizoguchi N, Say L, et al. (2013)
Understanding Global Trends in Maternal Mortality. Int Perspect Sex Reprod Health 39(1): 32-41.

3. Véronique Filippi, Doris Chou, Carine Ronsmans, Wendy Graham, Lale Say (2015) Levels and Causes of Maternal Morbidity and Mortality. p. 1-31.

4. (2015) Millennium Development Goals Report 2014 Ethiopia. Ethiopia NPCatUNi, pp. 1-103.

5. Agency CS (2016) Ethiopia Demographic and Health Survey 2016. pp. $1-516$.

6. Godefay H, Byass P, Graham WJ, Kinsman J, Mulugeta A (2015) Risk Factors for Maternal Mortality in Rural Tigray, Northern Ethiopia: A Case-Control Study. PLoS One 10(12): 1-12.

7. (2014) Maternal Death Surveillance and Response (MDSR) Technical Guideline. Health FDRoEMo, p. 1-75.

8. (2015) Trends in Maternal Mortality: 1990 to 2015 Estimates by WHO, UNICEF, UNFPA, World Bank Group and the United Nations Population Division Trends in maternal mortality. WHO, p. 1-77.

9. (2015) HSTP Health Sector Transformation Plan. Health TFDRoEMo, p. $1-182$.

10. Ujah IA, Aisien OA, Mutihir JT, Vanderjagt DJ, Glew RH, et al. (2005) Factors Contributing to Maternal Mortality in North-Central Nigeria: A Seventeen-year Review. Afr J Reprod Health 9(3): 27-40.

11. Mulama, Lihongeni N (2015) Analysis of Causes and Risk Factors Associated with Maternal Deaths in Namibia. p. 1-66.

12. Illah E, Mbaruku G, Masanja H, Kahn K (2013) Causes and Risk Factors for Maternal Mortality in Rural Tanzania - Case of Rufiji Health and Demographic Surveillance Site (HDSS). Afr J Reprod Health 17(3): 119-130.

13. Olopade FE, Lawoyin TO (2008) Maternal Mortality in a Nigerian Maternity Hospital. African Journal of Biomedical Research 11: 267-273.

14. Tegene Legese, Kebadnew Mulatu, Tensay Kahsay (2016) Trends and Determinants of Maternal Mortality in Mizan-Tepi University Teaching and Bonga General Hospital from 2011 - 2015: A Case Control Study. Health Science Journal 10(5): 1-8.

\section{Your next submission with Juniper Publishers will reach you the below assets}

- Quality Editorial service

- Swift Peer Review

- Reprints availability

- E-prints Service

- Manuscript Podcast for convenient understanding

- Global attainment for your research

- Manuscript accessibility in different formats

( Pdf, E-pub, Full Text, Audio)

- Unceasing customer service

Track the below URL for one-step submission https://juniperpublishers.com/online-submission.php 